\title{
25 VISUAL ELEMENTS IN THE DISCOURSE ON INFORMATION TECHNOLOGY
}

\author{
Mark Ackerman \\ University of Michigan \\ Ann Arbor, Michigan \\ U.S.A. \\ Brian T. Pentland \\ Michigan State University \\ East Lansing, Michigan \\ U.S.A. \\ Sajda Qureshi \\ University of Nebraska at Omaha \\ Omaha, Nebraska \\ U.S.A. \\ Elaine K. Yakura \\ Michigan State University \\ East Lansing, Michigan \\ U.S.A.
}

\section{INTRODUCTION}

Discourse is critical to organizations as well as to information technology in a variety of ways, as the literature attests (Alvesson and Karreman 2000; Beech 2000; Benders et al. 1998; Button and Sharrock 1995; Oswick et al. 2000; Rachel and Woolgar 1994). But there is an interesting new catch: the ways we talk about technology, and the content of the technology itself, are increasingly multimodal, involving graphical as well as textual elements (Kress et al. 1997).

The purpose of this panel is to explore the significance of this obvious (but easily overlooked) visual aspect of IT discourse. The panel draws on examples from a variety of different contexts. After a brief orientation to the general themes of the panel, Yakura examines the issue of multimodal representation in the familiar domain of IT consulting. Ackerman addresses image and discourse in a more esoteric context: astrophysics. Qureshi applies a similar perspective to the world of virtual communities. Pentland will offer some observations 
about the problems and possibilities of this line of research. Our goal is to provide examples sufficiently succinct and provocative that a significant portion of the session can be devoted to discussion and issues raised by the audience.

\section{YAKURA: DESIGNING THE MULTIMODAL TEXT: DISCURSIVE PRACTICES OF IT CONSULTANTS}

IT consultants produce all manner of materials about their services as well as their clients in the course of a consulting engagement. This presentation will explore the multimodal aspect of these materials. The use of the visual in presentations helps viewers fill in information not actually in the presentation. In her discussion of advertising visuals, for example, Barry (1997, p. 279) argues that visuals are especially effective in this regard because they are more easily processed than other forms of communication:

Advertising images thus act as condensed cultural symbols, visually reduced statements that suggest a storyline that targeted consumers complete in their own imaginations, with themselves as the leading character, although significantly the product remains the hero.

The content of the discursive material is made up of text as well as graphical elements (such as pictures, or graphical images such as boxes or arrows). These multimodal texts have become ubiquitous in our everyday life, in newspapers, magazines, television broadcasts, and the Internet. Stroupe (2000) has also commented on the "verbal-visual hybridity" of texts such as Web pages, and argues that scholars, with their tendency to ignore the visual in favor of the written, are missing essential elements and channels of communication. These multimodal texts are obvious to the viewer or reader, and thus both more and less visible in their presentation. Multimodal IT consulting material is thus both obvious, as well as value-added, and the elements of the modality that contribute to these characteristics will be illustrated and analyzed.

\section{ACKERMAN: ASTROPHYSICISTS AT THE DISCURSIVE BRINK: TECHNOLOGY AND STARS}

IT brings with it new capabilities for organizational discourse and discursive memory. The astrophysics world is currently constructing Virtual Observatories, global, federated data repositories in a next-generation grid network. The goal is to turn astrophysics from a case-based science into a statistically based science by obtaining large enough samples of similarly described phenomenon. 
This is a social world teetering between the discursive ideology of science, with its promotion of open analysis and the free dissemination of results, and the permanence, visibility, and ambiguity inherent in multiple representations. For example, all data is now mediated by software-space-based instruments may measure only photon hits. To reuse these data, astrophysicists must now ask who gets to denote the quality of various data modalities: raw data, calibrated data, analyzed data, or analyzed data? This talk will discuss how IT is reinstitutionalizing the relation between scientific work and its data.

\section{QURESHI: THE VISUAL SIDE OF VIRTUAL COMMUNITY}

The design, tools, and interfaces of the Web sites on which virtual communities emerge and operate has an increasingly visual component. In addition to the text (which is becoming less dominant), the layout of the Web sites is an integral part of the identity of the virtual communities. Visual images (pictures, places, and collaborative tools) and the things that are done with them shape the conversations (these can also be visually developed), as well as the persona that are projected on the electronic spaces. Visual images (alongside the use of text) are used to communicate thoughts and ideas, project identities that may be different from reality, and shape the collective norms and values of communities that exist on virtual spaces. Through the combined use of images, text, and collaborative tools, such communities appear to have the power to mobilize many minds and resources toward joint effect. This brings forth more diverse and interesting ways in which virtual communities take shape. But these qualities may also allow deception and illicit practices not yet known to us.

\section{PENTLAND: NARRATIVE ANALYSIS OF TECHNICAL FAIRY TALES}

The marketing and implementation of new technology is always accompanied by stories: what it will do, what it won't do, how great it will be once it gets working. Stories may be produced by a wide variety of participants: sales people, prospective users, technicians, managers, and so on. Before implementation, the stories describe an unknown situation: what will happen if we install this new technology? After implementation, they describe a situation that may still be open to interpretation. Like fairy tales, such stories often feature villains, fairy godmothers, and significant elements of magic. And like fairy tales, they often contain images or graphics that bring them to life. 
The question is, what can these technical fairy tales tell us about new technology? Are the images central or incidental? We are seeing increasing interest in discursive analysis, as illustrated by the theme of this conference. The goal here is to assess the limits and possibilities of this line of research in light of the fact that the stories are increasingly mult-modal, including visual as well as traditional textual elements.

\section{REFERENCES}

Alvesson, M., and Karreman, D. "Varieties of Discourse: On the Study of Organization through Discourse Analysis," Human Relations (53:9), 2000, pp. 1125-1137.

Barry, A. M. Visual Intelligence: Perception, Image, and Manipulation in Visual Communication. Albany, NY: State University of New York Press, 1997.

Beech, N. "Narrative Styles of Managers and Workers: A Tale of Star-Crossed Lovers," Journal of Applied Behavioral Science (36:2), 2000, pp. 210-228.

Benders, J., van den Berg, R.-J., and van Bijsterveld, M. "Hitch-Hiking on Hype: Dutch Consultants Engineering Re-engineering," Journal of Organizational Change Management (11:3), 1998, pp. 201.

Button, G., and Sharrock, W. "Practices in the Work of Ordering Software Development," in A. Firth (ed.), The Discourse of Negotiation: Studies of Language in the Workplace, Tarrytown, NY: Pergamon Press, 1995.

Grant, D., Keenoy, T., and Oswick, C. (Eds.). Discourse and Organization. Thousand Oaks, CA: Sage, 1998.

Kress, G., Leite-Garcia, R., and van Leeuwen, T. "Discourse Semiotics," in T. A. van Dijk (ed.), Discourse as Structure and Process, Vol. 1. Newbury Park, CA: Sage, 1997, pp. 257-289.

Oswick, C., Keenoy, T. W., and Grant, D. "Discourse, Organizations and Organizing: Concepts, Objects and Subjects," Human Relations (53:9), 2000, pp. 1115-1123.

Rachel, J., and Woolgar, S. "The Discursive Structure of the Social-Technical Divide: The Example of Information Systems Development," Sociological Review (43:2), 1994, pp. 251273.

Stroupe, C. "Visualizing English: Recognizing the Hybrid Literacy of Visual and Verbal Authorship on the Web," College English (62:5), 2000, pp. 607-632.

\section{About the Panelists}

Mark Ackerman is an associate professor in the School of Information and the Department of Electrical Engineering and Computer Science at the University of Michigan. Previously, he was a principal research scientist at MIT's Laboratory for Computer Science and an associate professor at the University of California, Irvine, in the Computing, Organizations, Policy, and Society group. He has published on the sociology of information, computer-supported cooperative work, organizational memory, knowledge management, virtual communities, and other human-computer topics. Mark can be reached by e-mail at ackerm@umich.edu. 
Brian T. Pentland is an associate professor in the Department of Accounting and Information Systems at Michigan State University and a member of IFIP 8.2. He received his Ph.D. in Management from the Massachusetts Institute of Technology in 1991 and S.B. in Mechanical Engineering from the Massachusetts Institute of Technology in 1981. His publications have appeared in Academy of Management Review, Accounting, Organizations and Society, Administrative Science Quarterly, Management Science, Organization Science, Technology Studies, and elsewhere. Brian can be reached by e-mail at pentlan2@msu.edu.

Sajda Qureshi is an associate professor in the Information Systems Department of the Faculty of Information Systems and Technology at the University of Nebraska at Omaha. She was assistant professor at the Department of Decision and Information Sciences of the Faculty of Management at Erasmus University Rotterdam, The Netherlands. She holds a Ph.D. in Information Systems from the London School of Economics and Political Science at the University of London. She has been coordinator of the Commonwealth Network of Information Technology for Development, has lectured at the MIS Department of the University of Arizona and has been involved in various consultancy projects in Italy and the UK. She has over 40 publications in journals such as Group Decision and Negotiation, Information Infrastructure and Policy, and Communications of the ACM, books published by Prentice Hall, SpringerVerlag, Chapman \& Hall, and North-Holland, and conferences such as the International Conference on Information Systems and the Hawaii International Conference on Systems Sciences. Her research interests include the use of electronic communication technologies to support coordination and decisionmaking processes within international networks and network organizations. Sajda can be reached by e-mail at squreshi@unomaha.edu.

Elaine K. Yakura is an assistant professor at the School of Labor and Industrial Relations at Michigan State University. She received her Ph.D. in Organization Studies (MIT Sloan School of Management), J.D. (Boalt Hall, University of California, Berkeley), and B.A. in Economics (Yale University). Her research interests include the study of difference and power in organizations using long-term qualitative research methods, and her fieldwork includes studies of information technology consultants and nuclear power plants in Japan and the U.S. Her recent articles include "Charting Time: Timelines as Temporal Boundary Objects," forthcoming in the October 2002 issue of the Academy of Management Journal, and "Billables: The Meaning of Time in Consulting" in the American Behavioral Scientist. Elaine can be reached by e-mail at yakura@msu.edu. 